\title{
Dimensional analysis of human saphenous vein grafts: Implications for external mesh support
}

Paul Human, PhD, Thomas Franz, PhD, Jacques Scherman, MBChB, Lovendran Moodley, MBChB, and Peter Zilla, MD, PhD

Objective: Constrictive external mesh support of vein grafts was shown to mitigate intimal hyperplasia in animal experiments. To determine the degree of constriction required for the elimination of dimensional irregularities in clinically used vein grafts, a detailed anatomic study of human saphenous veins was conducted.

Methods: In 200 consecutive patients having coronary artery bypass grafting, harvested saphenous veins (length $34.4 \pm 10.8 \mathrm{~cm}$ ) were analyzed regarding diameter irregularities, side branch distribution, and microstructure.

Results: The mean outer diameter of surgically distended saphenous veins was $4.2 \pm 0.6 \mathrm{~mm}$ (men, $4.3 \pm 0.6 \mathrm{~mm}$ vs women, $3.9 \pm 0.5 \mathrm{~mm} ; P<.0001$ ). Although the outer diameter significantly decreased over the initial $18 \mathrm{~cm}$ $(-7.6 \% ; P<.0001)$, the overall increase between malleolus and thigh was not significant $(+11.2 \%)$. Smaller-diameter veins $(<3.5 \mathrm{~mm})$ had more pronounced diameter fluctuations than larger veins $(31.8 \% \pm 11.0 \% \mathrm{vs} 21.2 \%$ $\pm 8.8 \% ; P<.0001$ ), with more than $71 \%$ of all veins showing caliber changes of more than $20 \%$. There was 1 side branch every $5.4 \pm 4.3 \mathrm{~cm}$, with a significantly higher incidence between 20 and $32 \mathrm{~cm}$ from the malleolus $(P<.0001$ to distal, $P<.0004$ to proximal). Generally, women had more side branches than men $(0.30 \pm 0.15$ $\mathrm{cm}^{-1}$ vs $\left.0.25 \pm 0.12 \mathrm{~cm}^{-1} ; P=.0190\right)$. Thick-walled veins $(565.7 \pm 138.4 \mu \mathrm{m})$ had a significantly higher number of large side branches $(P<.0001)$, and thin-walled veins $(398.7 \pm 123.2 \mu \mathrm{m})$ had significantly more small side branches $(P<.0001)$. Pronounced intimal thickening ("cushions") was found in $28 \%$ of vessels $(119.8 \pm 28.0$ $\mu \mathrm{m}$ vs $40.1 \pm 18.2 \mu \mathrm{m} ; P<.0001)$.

Conclusion: Although the preferential location of side branches may be addressed by the deliberate discarding of infragenicular vein segments, a diameter constriction of $27 \%$ on average would eliminate diameter irregularities in $98 \%$ of vein grafts.

With the advent of vascular surgery bypass procedures, reversed saphenous vein grafts became one of the most widely performed operations worldwide. Yet, saphenous vein grafts have a 10 -year failure rate of $30 \%$ to $41 \%$ in the coronary position $^{1,2}$ and-even worse-a 5-year failure rate of $32 \%$ to $47 \%$ in the infrainguinal position. ${ }^{3-5}$ The foremost pathologic mechanism behind failing vein grafts is intimal hyperplasia, mainly triggered by wall structures and anatomic dimensions that are ill-suited to accommodate arterial hemodynamics. Although diffuse intimal hyperplasia is largely an early response to the low shear forces and high circumferential stresses resulting from the diameter mismatch between vein graft and host artery, focal intimal hyperplasia often develops into progressive stenoses, ultimately resulting in graft occlusion. In search of mechanisms behind focal intimal

\footnotetext{
From the Christiaan Barnard Department of Cardiothoracic Surgery, University of Cape Town, Observatory, South Africa.

Dr Zilla reports royalty agreements and grant support from Medtronic. Drs Human and Franz report salary and grant support from Medtronic. The Medtronic grant also funded development of an external mesh support for vein grafts.

Received for publication March 11, 2008; revisions received Sept 5, 2008; accepted for publication Oct 3, 2008.

Address for reprints: Peter Zilla, MD, PhD, Christiaan Barnard Department of Cardiothoracic Surgery, Cape Heart Centre, Faculty of Health Sciences, University of Cape Town, Anzio Road, 7925 Observatory, South Africa (E-mail: Peter.Zilla@ uct.ac.za).

J Thorac Cardiovasc Surg 2009;137:1101-8

$0022-5223 / \$ 36.00$

Copyright (c) 2009 by The American Association for Thoracic Surgery

doi:10.1016/j.jtcvs.2008.10.040
}

proliferation, irregular luminal dimensions were shown to play a key role. By causing eddy blood flow, which is associated with areas of low fluid shear stress and increased shear gradients, ${ }^{6}$ luminal irregularities are main culprits of focal intimal hyperplasia. ${ }^{7}$

To eliminate the fluid dynamic triggers of both diffuse and focal intimal hyperplasia, the concept of a constrictive external support mesh for vein grafts was suggested as early as in 1963. ${ }^{8}$ By constricting the vein graft diameter, these meshes were expected to mitigate both diffuse intimal hyperplasia, through higher-flow velocity and thus higher shear forces, and focal intimal hyperplasia, through the elimination of luminal irregularities. Although this concept of vein graft constriction was experimentally confirmed over time, ${ }^{9-16}$ other aspects such as mesh material and structure also emerged as factors influencing intimal hyperplasia. By using synthetic wraps of different porosity, 1 group even found loose-fitting support structures to be most effective, ${ }^{17-21}$ and others confirmed the importance of constriction. ${ }^{9,11-13,22}$ Nonetheless, when protective mechanisms were narrowed to mainly hemodynamic principles through the use of rather inert metal meshes, ${ }^{15,23}$ moderate constriction was found to be essential. ${ }^{15}$ However, the extent to which human saphenous veins would need to be constricted to eliminate diameter irregularities remained vague due to assumptions surrounding their anatomy. The present study therefore analyzed a cohort of clinically harvested saphenous veins of 200 consecutive patients with regard to 


\section{Abbreviations and Acronyms \\ BMI = body mass index \\ $\mathrm{CABG}=$ coronary artery bypass grafting \\ $\mathrm{OD}=$ outer diameter}

diameter irregularities, branches, and intimal thickening. Furthermore, morphologic findings were correlated with demographic data, creating additional awareness for anatomic peculiarities of saphenous veins, which may have an impact on their use in cardiovascular surgery.

\section{PATIENTS AND METHODS \\ Patient Cohort}

The study was approved by the human ethics committee of the University of Cape Town with informed consent obtained from all patients. In 200 consecutive patients (mean age $60.0 \pm 8.5$ years, range $38-79$ years; mean weight $80.3 \pm 15.8 \mathrm{~kg} ; 65.0 \%$ men, $35.0 \%$ women; $65.8 \%$ mixed race, $28.2 \%$ Caucasian, $3.8 \%$ Asian, and $2.2 \%$ black) having coronary artery bypass grafting (CABG), the outer diameter (OD) of the saphenous vein was assessed during harvesting. The majority of patients were either overweight $\left(45.7 \%\right.$; defined as body mass index [BMI] $\left.2-30 \mathrm{~kg} / \mathrm{m}^{2}\right)$ or obese $(32.4 \%$; defined as BMI $\geq 30 \mathrm{~kg} / \mathrm{m}^{2}$ ) with BMIs ranging from 19.0 to $50.7 \mathrm{~kg} / \mathrm{m}^{2}$ (mean $28.8 \pm 5.0$ ). Cardiovascular risk factors included diabetes $(34.2 \%)$, a positive family history of coronary disease $(62.8 \%)$, hypercholesterolemia $(70.6 \%)$, hypertension $(76.1 \%)$, and smoking $(77.0 \%)$. The planned length of vein to be harvested was determined by the surgeon's predicted graft requirements. The average number of grafts/distal anastomoses was $2.6 \pm 0.7 / 4.1 \pm 1.3(2.7 \pm 0.7 / 4.1 \pm 1.4$ for on-pump procedures $[\mathrm{n}=$ $251]$ and $2.5 \pm 0.7 / 4.3 \pm 1.1$ for off-pump procedures $[\mathrm{n}=49])$ per patient $(1.7 \pm 0.6 / 2.0 \pm 0.8$ for saphenous veins; $0.9 \pm 0.4 / 1.0 \pm 0.5$ for internal thoracic artery grafts and $0.1 \pm 0.2 / 0.1 \pm 0.3$ for radial artery grafts).

\section{Vein Morphometry}

Macroscopy. Measurements were taken with a caliper every $2 \mathrm{~cm}$ from the malleolar cannulation site at a time when all side branches had been ligated and the vein was still in situ. The intravascular pressure was monitored during routine syringe distension $(342 \pm 37 \mathrm{~mm} \mathrm{Hg})$. In all patients, the right-sided saphenous vein was harvested and measured. In $14.5 \%$ of patients, the right-sided harvest had to be abandoned before the required graft length was obtained due to too small a diameter. The remaining graft segment was then harvested from the left leg. To exclude the possibility of a short intervening segment of unsuitable vein quality, right-sided harvests were usually continued for another $3.5 \pm 3.0 \mathrm{~cm}$ before the final decision to continue on the left leg was made, thus including the full extent of caliber change in the dataset.

Assessment of the variations in OD. To provide a means of determining the magnitude and frequency of fluctuations in OD along the length of the veins, a customized algorithm (Filemaker Pro, Santa Clara, Calif) was designed, which iteratively examined the percentage changes in $\mathrm{OD}$ of each vein commencing at the ankle, whether larger or smaller, against prevailing maximum and minimum diameters prior to each segment. The algorithm hypothetically "cut" the vein into virtual segments if, at any point, the percentage change exceeded the set percentage change limits. The lengths of these hypothetical segments were then recorded. Percentage changes were always related to the larger diameter according to the formulae $\left[\left(\mathrm{OD}-\mathrm{OD}_{\min }\right) / \mathrm{OD} \times 100\right.$ for distended points and $\left(\mathrm{OD}_{\max }-\mathrm{OD}\right) / \mathrm{OD}_{\max } \times$ 100 for constricted points, where OD represented the OD being examined and $\mathrm{OD}_{\max }$ and $\mathrm{OD}_{\min }$, respectively, represented the prevailing maximum and minimum $\mathrm{OD}$ values].
Side branch classification. During in situ measurement of the OD of each vein along its length, side branches were simultaneously classified into arbitrarily defined small, medium, and large size categories and recorded together with their location and frequency.

\section{Light Microscopy}

At the end of coronary bypass surgery, 1-cm-long saphenous vein samples, which were taken $2 \mathrm{~cm}$ from the cannulation site and briefly stored in heparinized blood, were gently slid over appropriately sized, tapered plastic pipette tips to maintain the vessel diameter during overnight fixation. Subsequently, specimens were processed and paraffin embedded.

Routine light microscopic sections were stained with hematoxylin and eosin, elastic Masson trichrome (for determination of layer boundaries), and modified Movat's (for distinction between intimal hyperplasia and nonhyperplastic intimal cushions). A Nikon E 1000M light microscope and a Nikon Coolscope (Nikon, Tokyo) were used for morphometric analyses.

The 3 wall layers were relatively easily discernable in all veins. Image analysis was performed using Adobe Photoshop version 7.0 (San Jose, Calif) and IPTK version 5 plug-ins (Reindeer Graphics, Asheville, NC) on tiled images assembled from an array of digital frames captured individually at $10 \times$ magnification and using Eclipse Net (Laboratory Imaging, Prague, Czech Republic) software. Cross-sectional wall thickness, the thickness of the media and its smooth muscle component area, as well as intimal cushions were manually delineated and quantified.

\section{Statistical Methods}

Patient demographics and relevant clinical data were recorded on an electronic patient database system developed in-house (Filemaker Pro, Filemaker Inc, Santa Clara, Calif). Laboratory-based morphometric analysis data were entered into a linked relational database thus allowing cross-referencing of laboratory analysis data with selected demographic data while maintaining patient confidentiality at all times through the use of sample coding.

All continuous numerical data are expressed as means \pm standard deviation. Shapiro-Wilk testing for normal distribution of data was performed to confirm validity of parametric testing. Square root transformation was applied where indicated. One-way analysis of variance was used for multiple group effect testing, and Student $t$ test was performed for binomial post hoc inference testing. Multiple comparisons, where indicated, were performed using Tukey-Kramer honestly significant difference (HSD) testing. All statistical analyses were performed using the statistical package JMP (version 6.02; SAS, Cary, NC) on an Apple PowerPC-based Macintosh computer (Cupertino, Calif).

\section{RESULTS}

\section{Macroscopic Anatomy}

The mean length of harvested saphenous vein(s) per patient (including the left-sided segments in patients who needed bilateral harvest) was $34.4 \pm 10.8 \mathrm{~cm}$ (range 12$74 \mathrm{~cm}$ ). The mean length of unilaterally harvested saphenous veins $(85.5 \%$ of all patients) was $31.1 \pm 10.1 \mathrm{~cm}$. The average segment length of the right-sided saphenous vein of those $14.5 \%$ of patients where poor-quality criteria made bilateral harvest necessary was $22.6 \pm 5.9 \mathrm{~cm}$. The number of harvested right-sided saphenous veins declined with increasing distance from the ankle (Figure 1). The OD of individual, fully distended veins ranged from an absolute minimum of $2.0 \mathrm{~mm}$ to an absolute maximum of $7.0 \mathrm{~mm}$. The grand mean OD for all veins was $4.2 \pm 0.6 \mathrm{~mm}$ (range $2.9-6.5 \mathrm{~mm}$ ). The $95 \%$ tolerance intervals $(90 \%$ probability) remained 


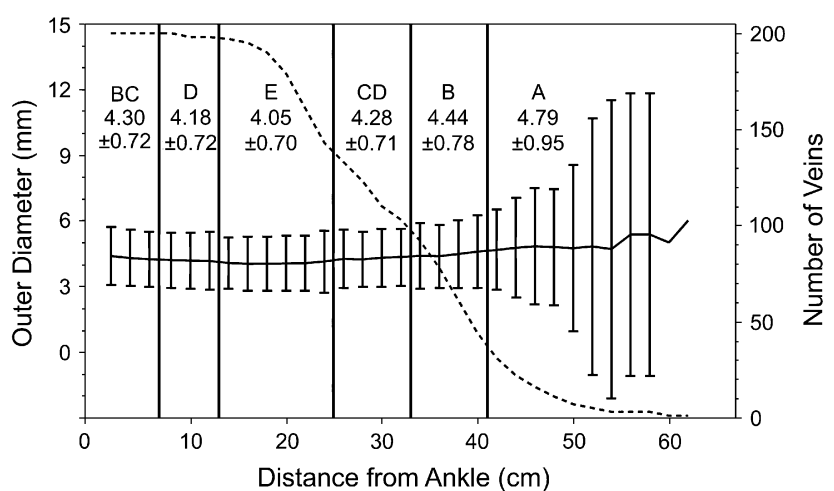

FIGURE 1. Dimensional analysis of saphenous veins of 200 consecutive patients having coronary artery bypass grafting. Outer diameters were measured in situ during vein harvest at routine surgical syringe distension. Mean outer-diameter values are shown as a function of distance from the ankle. Error bars represent $95 \%$ confidence intervals. Vertical lines delineate statistically significant cut points between segments of different diameter (Tukey-Kramer honestly significant difference [HSD] test) with capital letters A through E indicating statistical significance. Regions not sharing identical capital letters are statistically distinct $(P<.05)$.

within $1.5 \mathrm{~mm}$ of this mean value for the first $32 \mathrm{~cm}(\mathrm{n}=$ $103 / 200$ primary veins) and within $2.0 \mathrm{~mm}$ up to $40 \mathrm{~cm}$ $(\mathrm{n}=31 / 200)$. Overall, the OD decreased by $7.6 \% \pm$ $14.2 \%$ over the initial $18 \mathrm{~cm}$ from the malleolus (from $4.4 \pm 0.7 \mathrm{~mm}$ to $4.0 \pm 0.7 \mathrm{~mm} ; P<.0001$ ) but overall increased over a length of $40 \mathrm{~cm}$ by $11.2 \% \pm 12.8 \%$ (to $4.6 \pm 0.8 \mathrm{~mm})$.

\section{Demographic Determinants}

Men had significantly larger mean ODs $(4.3 \pm 0.6 \mathrm{~mm}$ vs $3.9 \pm 0.5 \mathrm{~mm}$, respectively; $P<0.0001)$ and OD ranges $(1.3$ $\pm 0.7 \mathrm{~mm}$ vs $1.1 \pm 0.5 \mathrm{~mm}$, respectively; $P=.0084$ ) than women. This phenomenon may be a reflection of weight because men were expectedly heavier $(83.9 \pm 15.3 \mathrm{~kg}$ vs 73.4 $\pm 14.6 \mathrm{~kg} ; P<.0001)$ than women, and partition modeling revealed significantly larger mean ODs $(4.3 \pm 0.6 \mathrm{~mm}$ vs 3.9 $\pm 0.6 \mathrm{~mm} ; P=.0020)$ and maximum ODs $(5.0 \pm 0.7 \mathrm{~mm}$ vs $4.6 \pm 0.7 \mathrm{~mm} ; P=.0047$ ) for body weights above $69.5 \mathrm{~kg}$. In contrast, height had no influence on the mean OD of saphenous veins.

\section{OD Fluctuation}

Fluctuations in the OD of veins were largely gradual with more distinct changes occurring immediately below (at 22 $\mathrm{cm}$ ) and immediately above the knee (at $36 \mathrm{~cm}$ ).

Over the entire harvested length, the average difference between the widest and narrowest diameter of individual veins was $1.25 \pm 0.64 \mathrm{~mm}$ or $25.3 \% \pm 11.0 \%$. Generally, smaller-diameter veins with minima of less than $3.5 \mathrm{~mm}$ showed more pronounced diameter fluctuations than larger ones $(31.8 \% \pm 11.0 \%$ vs $21.2 \% \pm 8.8 \% ; P<.0001)$. Very few veins were either of even calibers, with less than $10 \%$ diameter changes ( $8.5 \%$ of veins), or of extremely un-

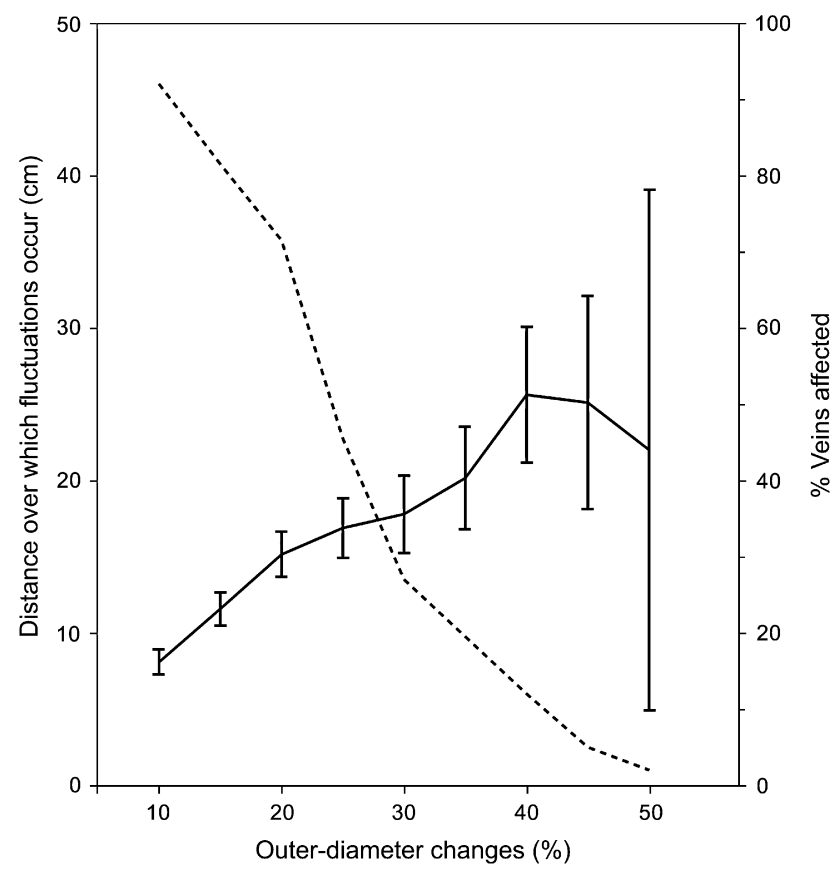

FIGURE 2. Incidence of outer-diameter fluctuations and distances over which they occur. The dashed line represents the percentage of veins that experienced diameter changes of a certain magnitude (right-sided y-axis). The solid line shows the average distance over which these diameter changes take place (left-sided y-axis). Error bars represent 95\% confidence intervals.

evenly calibers, with more than $40 \%$ or $50 \%$ diameter changes $(10.0 \%$ or $1.5 \%$ of veins, respectively). More than $71 \%$ of veins showed caliber changes of more than $20 \%$ and the interquartile range of diameter irregularities of harvested veins fell between $18.3 \%$ and $31.3 \%$. By hypothetically constricting the OD of veins to $3.5 \mathrm{~mm}$ (on average by $25.9 \% \pm 12.0 \%$ and by a maximum of $50 \%$ in any vein), caliber irregularities could be avoided in $98 \%$ of vein grafts due to the fact that the minimum OD of most veins was always more than half their maximum diameter.

Algorithm-based analysis characterized diameter changes of $\geq 10 \%, \geq 20 \%, \geq 30 \%, \geq 40 \%$, and $\geq 50 \%$ as occurring every $8.1 \pm 5.6 \mathrm{~cm}(4.0 \pm 2.7$ times per vein $), 15.1 \pm 8.8$ $\mathrm{cm}(1.9 \pm 1.4$ times per vein $), 17.8 \pm 9.2 \mathrm{~cm}(1.4 \pm 0.9$ times per vein), $25.6 \pm 10.6 \mathrm{~cm}(1.2 \pm 0.5$ times per vein), and $22.0 \pm 10.7 \mathrm{~cm}(1.0 \pm 0$ times per vein), respectively (Figure 2).

\section{Side Branch Distribution}

On average, there was 1 side branch every $5.3 \pm 4.3 \mathrm{~cm}$. The largest proportion of tributaries fell into the medium category $(45.6 \% \pm 27.0 \%)$ with 1 branch every $15.3 \pm 10.5$ $\mathrm{cm}$, followed by large category $(33.0 \% \pm 27.0 \%)$ with 1 branch every $11.3 \pm 8.7 \mathrm{~cm}$. Only one-fifth of tributaries were classified as small $(21.4 \% \pm 21.4 \% ; 1$ branch every $17.2 \pm 12.0 \mathrm{~cm})$.

Apart from the immediate malleolar region, the highest incidence of side branches was found in the area below the 


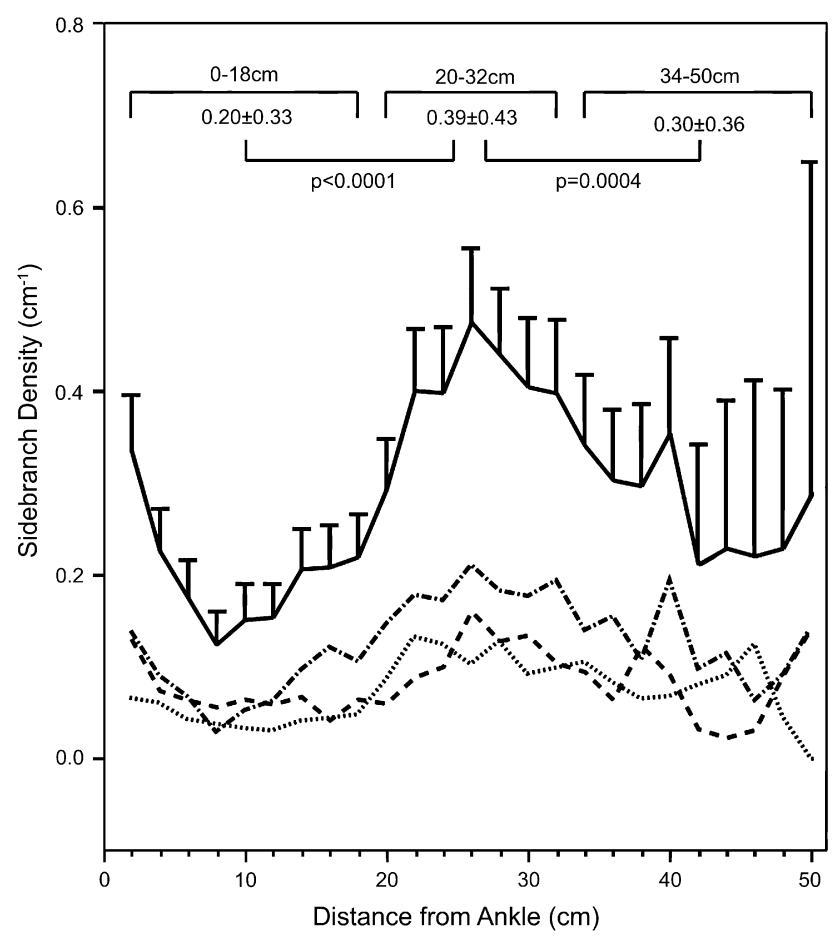

FIGURE 3. Distribution of side branches from the malleolus. Partitioning revealed a highly significant increase in the total number of side branches (solid line) between 22 and $32 \mathrm{~cm}$ from the ankle. When branches were categorized into large (dashed line), medium (dashed/dotted line), and small (dotted line) sizes, their densities followed a similar distribution pattern with a relatively equal incidence between the groups. Error bars represent $95 \%$ confidence intervals.

knee (Figure 3), between 20 and $32 \mathrm{~cm}$ from the ankle $(0.23$ $\pm 0.15 \mathrm{~cm}^{-1}$ vs $0.50 \pm 0.34 \mathrm{~cm}^{-1}$ versus $0.41 \pm 0.29 \mathrm{~cm}^{-1}$ for $<20 \mathrm{~cm}, 20-32 \mathrm{~cm}$, and $>32 \mathrm{~cm}$, respectively; $P<$ $.0001)$. When the size of the tributaries was considered, the frequency of small and medium-sized side branches peaked at $22 \mathrm{~cm}$ from the ankle and that of large ones at $26 \mathrm{~cm}$. On the whole, larger-diameter veins had a significantly higher number of side branches as there was a direct correlation of incidence of tributaries and increased maximum OD $(P=.0009)$, mean OD $(P=.0126)$, and OD range $(P=.0122)$.

Demographically, the side branch density was higher in women than in men $\left(0.30 \pm 0.15 \mathrm{~cm}^{-1}\right.$ vs $0.25 \pm 0.12$ $\left.\mathrm{cm}^{-1} ; P=.0190\right)$ but further analysis revealed that this only applied to smokers $\left(0.33 \pm 0.15 \mathrm{~cm}^{-1}\right.$ vs $0.25 \pm 0.13$ $\left.\mathrm{cm}^{-1} ; P=.0023\right)$ but not to nonsmokers $(0.24 \pm 0.13$ $\mathrm{cm}^{-1}$ vs $\left.0.23 \pm 0.08 \mathrm{~cm}^{-1} ; P=.90\right)$. None of the other risk factors were predictors for side branch density. No differences between men and women were observed with respect to side branch size.

Histomorphometrically, thick-walled veins had a significantly higher number of large side branches $(P<.0001)$, and thin-walled veins had significantly more small side branches $(P<.0001)$ than other veins.

\section{Microscopic Anatomy}

In almost one-quarter of veins, distinct intimal cushions protruded into the lumen (Figure 4). On Movat stains, these intimal cushions regularly stained negative for glycosaminoglycans, rather showing longitudinally oriented smooth muscle cells loosely embedded in a collagen-rich extracellular matrix. Overall, the average thickness of intimal tissue was $64.0 \pm 46.5 \mu \mathrm{m}$ ranging from a delicate layer as thin as $9.3 \mu \mathrm{m}$ to distinct cushions as thick as $275.2 \mu \mathrm{m}$. Partition modeling defined the cut-point between mild and marked intimal thickening at $80 \mu \mathrm{m}$. Marked intimal thickening (defined as $>80 \mu \mathrm{m}$ ) occurred in $28 \%$ of vessels. The mean cross-sectional area of the intima of this subgroup was $1.32 \pm 0.43 \mathrm{~mm}^{2}$ (thickness $119.8 \pm 28.0 \mu \mathrm{m}$ ) compared with $0.44 \pm 0.22 \mathrm{~mm}^{2}$ (thickness $40.1 \pm 18.2 \mu \mathrm{m} ; P<.0001$, square root transformation) in the remaining $72 \%$ of veins. Furthermore, the entire vein wall was significantly thicker in the group with marked intimal thickening $(565.7 \pm 138.4 \mu \mathrm{m}$ vs $398.7 \pm 123.2 \mu \mathrm{m} ; P<.0001$ ) based on a proportionally increased thickness of the other 2 layers (media $207.3 \pm$ $65.9 \mu \mathrm{m}$ vs $159.2 \pm 65.4 \mu \mathrm{m}, P=.0014$; adventitia $236.7 \pm 96.1 \mu \mathrm{m}$ vs $195.6 \pm 68.7 \mu \mathrm{m}, P=.0187)$. Regardless of wall thickness, the proportion of smooth muscle cells versus extracellular matrix $(52.4 \% \pm 17.4 \%)$ in the media remained constant.

\section{Demographic Determinants}

Wall thickness and intimal thickness both showed a significant gender difference (wall thickness: men $476.7 \pm$ $145.9 \mu \mathrm{m}$ vs women $396.2 \pm 115.7 \mu \mathrm{m}, P=.0298$; intimal thickness: men $72.8 \pm 44.0 \mu \mathrm{m}$ vs women $48.6 \pm 38.8 \mu \mathrm{m}$, $P=.0341)$.

\section{DISCUSSION}

Cross-sectional diameter and luminal irregularities influence the fate of saphenous vein grafts. By affecting flow velocity, wall tension, and turbulences, they hold an ultimate key to patency. Yet, information on the anatomic and histologic variability within and between clinically harvested saphenous veins is scarce.

The few studies available on unimplanted human saphenous veins largely consist of small cohorts of patients focusing primarily on histologic, ${ }^{24,25}$ ultrastructural, ${ }^{24,26}$ and functional ${ }^{27-29}$ rather than macroanatomic aspects.

Motivated by the theoretical ability to reduce irregularities by constrictive external meshes, ${ }^{9-16}$ the present study aimed primarily at a baseline assessment of the diameter fluctuations of human saphenous vein grafts. By anatomically analyzing the saphenous veins of 200 consecutive patients having coronary artery bypass during harvest and correlating them with histomorphometric analyses, we determined that: 

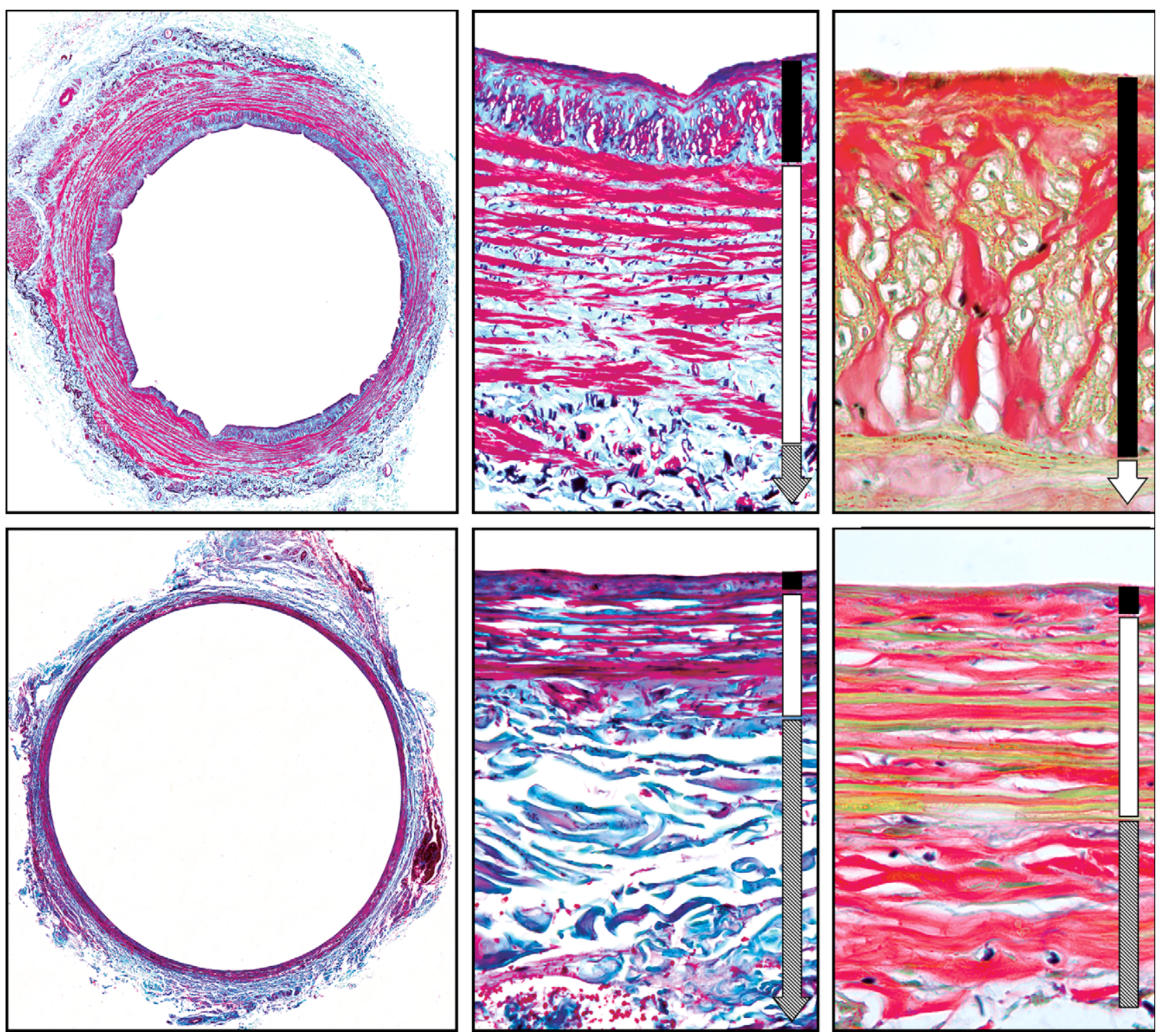

FIGURE 4. Histologic appearance of malleolar segments of human saphenous veins (black bar, intima; white bar, media; and gray bar, adventitia). Although the Masson's stains (left column/original magnification $\times 4$ and middle column/original magnification $\times 10$ ) allow us to distinguish between smooth muscle cells (red) and collagen (blue), Movat stains (right column/original magnification $\times 40$ ) were chosen to distinguish intimal "cushions" from true neointimal hyperplasia. Glycosaminoglycans—typical for neointimal hyperplasia—would have stained blue. Their absence supports the interpretation that cushions are anatomic rather than pathologic structures. Typically, thick-walled veins (top row) have a high propensity for intimal cushions, whereas thin-walled veins (bottom row) generally have delicate intimas.

- On average, only half a length of 1 saphenous vein was harvested per patient having CABG.

- Overall, the outer vein graft diameter increased only modestly from the malleolus toward the midthigh.

- The mean OD of saphenous veins was larger in men than in women.

- Distinct diameter fluctuations of between $20 \%$ and $30 \%$ were seen in 3 of 4 patients.

- Diameter fluctuations were more pronounced in smalldiameter than large-diameter veins.
- The incidence of side branches was approximately $1 \mathrm{ev}$ ery $5 \mathrm{~cm}$, with a peak density below the knee.

- Large-diameter veins had significantly more side branches than small-diameter veins.

- Pronounced intimal "cushions" were found in $28 \%$ of saphenous veins but were not an isolated phenomenon, and were rather a reflection of an overall increase in wall thickness, including the media.

- The thicker the wall of a saphenous vein, the larger its side branches. 
Given the fact that coronary surgery does not entirely depend on vein grafts but additionally utilizes arterial grafts, the length of harvested vein is usually shorter than in peripheral bypass surgery. Although the overall length of human saphenous veins between the upper ridge of the medial malleolus and the saphenofemoral junction was reported to be approximately $68 \mathrm{~cm},{ }^{27,30}$ the femoral epicondyle was shown to divide the vein into equal above- and belowknee halves of circa $34 \mathrm{~cm}^{30}$ Accordingly, a majority of our patients did not require more than the below-knee segment to be harvested as the length of vein taken was less than $34 \mathrm{~cm}$ in $54 \%$ of our patients. Nonetheless, longer veins were still harvested from a sufficient number of patients, thus providing a reasonable reflection of the anatomy of the human saphenous vein up to a length of at least $48 \mathrm{~cm}$.

Because the immediate infraepicondylar vein segment contained $1.4 \pm 1.3$ times more and up to a maximum of 5 times more side branches than a corresponding length of the above-knee section of the vein, one may consider harvesting longer veins to be able to discard this particularly side branch-rich segment. It was previously shown that the majority of side branches-regardless of whether they are large or small-are guarded by small microvalves. ${ }^{24} \mathrm{Be}-$ cause of their luminal location, these microvalves were suspected to cause local flow disturbances, aggravated by hyperplastic responses within the cusps. ${ }^{24,31}$ However, as much as the exclusion of the genicular segment of the saphenous vein may be appealing from the standpoint of future graft failure, an additional $12 \mathrm{~cm}$ of vein would add harvesting time, incision length, and infection risk.

Yet, the main focus of the present study was not on side branches but on diameter and diameter fluctuations of the saphenous vein. As these 2 parameters influence both flow velocity and flow characteristics, they are key determinants of intimal hyperplasia. Given the possibility of diameter reduction through constricting external meshes, ${ }^{8-16}$ insight into these anatomic aspects holds the promise of a lowered failure risk for vein grafts. Previously reported mean diameters of nonvaricose saphenous veins oscillated within the wide range of $<3.0 \mathrm{~mm}$ and $>7 \mathrm{~mm}$. $^{4,27,32-36}$ Because our cohort of 200 patients showed a narrower range of mean diameters, it is most probable that the extreme diameter differences previously reported were due to the different distension pressures used under experimental and clinical conditions. In some of these studies, very low pressures were chosen, which did not reverse the vein spasm, reflecting the concerns of the time that overdistension during harvest is a key contributor to vein graft failure. When distending the veins at pressures typically observed during surgical routine harvest of saphenous veins, ${ }^{37}$ the mean OD in our series of 200 primary veins was $4.2 \pm 0.6 \mathrm{~mm}$. Contrary to conventional wisdom, the overall mean increase in diameter from the malleolus to the thigh was no more than $11 \%$. Given the fact that individual diameter fluctuations by far exceeded this modest trend, one cannot conclude that above-knee segments necessarily have a larger OD than below-knee ones. Thus, the preferential use of distal vein segments for the grafting of smaller coronary branches (eg, obtuse marginal branch of the circumflex) and of proximal vein segments for larger coronary arteries (eg, main right $)^{38}$ does not appear to be of major benefit.

Because flow velocity determines shear stress and because low shear stress is a main trigger for intimal hyperplasia, ${ }^{39}$ diameter mismatch between vein grafts and their grafted arteries is a main trigger for intimal hyperplasia. Furthermore, low shear stress in the region of 5 dynes $/ \mathrm{cm}^{2}$ was additionally shown to lead to endothelial detachment. ${ }^{40}$ Based on a mean diastolic flow velocity of $26 \mathrm{~cm} / \mathrm{s}$ in coronary vein grafts of a comparable diameter ${ }^{41}$ it appears as if shear stresses of above 5 dynes $/ \mathrm{cm}^{2}$ are generally reached. However, given the fact that $68 \%$ of veins contained at least some segments that exceeded a calculated internal diameter of $3.55 \mathrm{~mm}$ - the dimension above which the shear stress in coronary vein grafts would remain below 5 dynes $/ \mathrm{cm}^{2}$ throughout the cardiac cycle-endothelial denudation is likely to occur in these areas postimplantation. Partial sloughing of endothelium postimplantation has been a well-described phenomenon, ${ }^{42}$ but it was only recently clearly related to large vein graft dimensions. ${ }^{15}$

Although mean diameters give an indication for the diameter mismatch between vein grafts and target arteries, diameter variations within a given vein graft may cause eddy blood flow and thus give rise to focal stenoses. ${ }^{7}$ By assessing the OD of saphenous veins over their entire length, we found almost 2 diameter fluctuations of more than $20 \%$ in $72 \%$ of vein grafts. Differences between the narrowest and the widest OD of individual veins were in average $30 \%$ of their mean diameter but in the most extreme, $10 \%$ of veins could be as pronounced as $61 \%$. These extreme diameter changes were hardly ever abrupt but occurred over long distances, moderating the expected influence on turbulences. In contrast, small-diameter oscillations of $10 \%$ occurred in average over distances of $8 \mathrm{~cm}$. Conversely, one could equalize the OD of $98 \%$ of vein grafts with an external mesh that constricts the veins by $27 \%$.

Histologically, we found a similar degree of variability in intimal cushions as previous authors. We chose the malleolar segment of the veins for histomorphometric analysis because it is known to be the site with the highest degree of intimal cushion formation ${ }^{43}$ and because it is the 1 segment left over in practically all coronary bypass procedures. Although it may not necessarily reflect the histomorphology of the entire saphenous vein, it allows some degree of extrapolation. Lacking positive labeling for GAGs on Movat stains, these often protruding "intimal cushions" were very rich in collagen and also showed mainly longitudinally embedded smooth muscle cells. Most ${ }^{2,25,30,44,45}$ but not all authors ${ }^{25,46}$ agree that intimal cushions are distinctly different from 
intimal hyperplasia. Our analysis also shows that well-developed intimal cushions are mainly a reflection of overall wall thickness, which itself correlates directly with vein diameter. Therefore, the larger the diameter, the thicker the vein wall and the more pronounced the intimal cushions. Both the positive correlation between intimal thickness and medial thickness ${ }^{44,45}$ as well as wall thickness and vein diameter ${ }^{47}$ confirm previous reports. This proportional increase of dimensions also highlights the fact that small-diameter veins are seldom thick-walled. It is this rare subgroup that was shown to have the highest propensity for occlusion ${ }^{47}$ and thereby caused the conviction among surgeons that all small-diameter veins have high occlusion rates.

In summary, the average saphenous vein harvested for coronary artery bypass procedures is $31 \mathrm{~cm}$ long and has an OD of $4.2 \mathrm{~mm}$, a wall thickness of $445 \mu \mathrm{m}$, and intimal cushions of $64 \mu \mathrm{m}$. Distinct irregularities result from an uneven distribution of side branches and the fact that an average saphenous vein encounters 1.9 diameter changes of up to $20 \%$ and 1.2 diameter changes of more than $40 \%$. Although preferential locations of side branches may be counteracted by the deliberate discarding of primarily infragenicular vein segments, fluctuations in OD may be addressed by constrictive external stenting. For a majority of vein grafts, a mild restriction by $27 \%$ would suffice.

\section{References}

1. FitzGibbon G, Leach A, Kafka H, Keon W. Coronary bypass graft fate: long-term angiographic study [see comments]. J Am Coll Cardiol. 1991;17:1075-80.

2. Campeau L, Enjalbert M, Lesperance J, Vaislic C, Grondin CM, Bourassa MG. Atherosclerosis and late closure of aortocoronary saphenous vein grafts: sequential angiographic studies at 2 weeks, 1 year, 5 to 7 years, and 10 to 12 years after surgery. Circulation. 1983;68(3 Pt 2):II1-7.

3. Veith F, Gupta S, Ascer E, White FS, Samson R, Scher L, et al. Six-year prospective multicenter randomized comparison of autologous saphenous vein and expanded polytetrafluoroethylene grafts in infrainguinal arterial reconstructions. J Vasc Surg. 1986;3:104-14.

4. Jackson M, Belott T, Dickason T, Kaiser W, Modrall J, Valentine R, et al. The consequences of a failed femoropopliteal bypass grafting: comparison of saphenous vein and PTFE grafts. J Vasc Surg. 2000;32:498-504; 504-5.

5. Szilagyi D, Hageman J, Smith R, Elliott J, Brown F, Dietz P. Autogenous vein grafting in femoropopliteal atherosclerosis: the limits of its effectiveness. Surgery. 1979;86:836-51.

6. Kim YH, Chandran KB, Bower TJ, Corson JD. Flow dynamics across end-to-end vascular bypass graft anastomoses. Ann Biomed Eng. 1993;21:311-20.

7. Liu S. Prevention of focal intimal hyperplasia in rat vein grafts by using a tissue engineering approach. Atherosclerosis. 1998;140:365-77.

8. Parsonnet V, Lari AA, Shah IH. New stent for support of veins in arterial grafts. Arch Surg. 1963;87:696-702.

9. Barra J, Volant A, Leroy J, Braesco J, Airiau J, Boschat J, et al. Constrictive perivenous mesh prosthesis for preservation of vein integrity. Experimental results and application for coronary bypass grafting. J Thorac Cardiovasc Surg. 1986; 92(3 Pt 1):330-6.

10. El-Kurdi MS, Hong Y, Stankus JJ, Soletti L, Wagner WR, Vorp DA. Transient elastic support for vein grafts using a constricting microfibrillar polymer wrap. Biomaterials. 2008;29:3213-20.

11. Meguro T, Nakashima H, Kawada S, Tokunaga K, Ohmoto T. Effect of external stenting and systemic hypertension on intimal hyperplasia in rat vein grafts. Neurosurgery. 2000;46:963-9; discussion 9-70.

12. Liu SQ, Moore MM, Yap C. Prevention of mechanical stretch-induced endothelial and smooth muscle cell injury in experimental vein grafts. J Biomech Eng. 2000; $122: 31-8$.
13. Karayannacos P, Hostetler J, Bond M, Kakos G, Williams R, Kilman J, et al. Late failure in vein grafts: mediating factors in subendothelial fibromuscular hyperplasia. Ann Surg. 1978;187:183-8.

14. Batellier J, Wassef M, Merval R, Duriez M, Tedgui A. Protection from atherosclerosis in vein grafts by a rigid external support. Arterioscler Thromb. 1993;13: 379-84.

15. Zilla P, Human P, Wolf M, Lichtenberg W, Rafiee N, Bezuidenhout D, et al. Constrictive external Nitinol meshes inhibit vein graft intimal hyperplasia in nonhuman primates. J Thorac Cardiovasc Surg. 2008;136:717-25.

16. Kohler T, Kirkman T, Clowes A. The effect of rigid external support on vein graft adaptation to the arterial circulation. J Vasc Surg. 1989;9:277-85.

17. Jeremy JY, Bulbulia R, Johnson JL, Gadsdon P, Vijayan V, Shukla N, et al. A bioabsorbable (polyglactin), nonrestrictive, external sheath inhibits porcine saphenous vein graft thickening. J Thorac Cardiovasc Surg. 2004;127:1766-72.

18. Dashwood MR, Angelini GD, Wan S, Yim A, Mehta D, Izzat MB, et al. Does external stenting reduce porcine vein-graft occlusion via an action on vascular nerves? J Card Surg. 2002;17:556-60.

19. Angelini GD, Lloyd C, Bush R, Johnson J, Newby AC. An external, oversized, porous polyester stent reduces vein graft neointima formation, cholesterol concentration, and vascular cell adhesion molecule 1 expression in cholesterol-fed pigs. J Thorac Cardiovasc Surg. 2002;124:950-6.

20. Jeremy JY, Dashwood MR, Mehta D, Izzat MB, Shukla N, Angelini GD. Nitric oxide, prostacyclin and cyclic nucleotide formation in externally stented porcine vein grafts. Atherosclerosis. 1998;141:297-305.

21. Vijayan V, Shukla N, Johnson J, Gadsdon P, Angelini G, Smith F, et al. Long term reduction of medial and intimal thickening in porcine saphenous vein grafts with a polyglactin biodegradable external sheath. J Vasc Surg. 2004;40:1011-9.

22. Moritz A, Magometschnigg H, Staudacher M, Ptakovsky H, Raderer F, Ullrich R et al. [Stented dilated or varicose veins as arterial bypass transplants: experimental and initial clinical results]. Vasa. 1991;20:222-9.

23. Zurbrugg H, Knollmann F, Musci M, Wied M, Bauer M, Chavez T, et al. The biocompound method in coronary artery bypass operations: surgical technique and 3-year patency. Ann Thorac Surg. 2000;70:1536-40.

24. Marin ML, Gordon RE, Veith FJ, Panetta TF, Sales CM, Wengerter KR. Human greater saphenous vein: histologic and ultrastructural variation. Cardiovasc Surg. 1994;2:56-62.

25. Milroy C, Scott D, Beard J, Horrocks M, Bradfield J. Histological appearances of the long saphenous vein. J Pathol. 1989;159:311-6.

26. Gundry S, Jones M, Ishihara T, Ferrans V. Intraoperative trauma to human saphenous veins: scanning electron microscopic comparison of preparation techniques. Ann Thorac Surg. 1980;30:40-7.

27. Ku DN, Klafta JM, Gewertz BL, Zarins CK. The contribution of valves to saphenous vein graft resistance. $J$ Vasc Surg. 1987;6:274-9.

28. McGregor E, Gosling M, Beattie DK, Ribbons DM, Davies AH, Powell JT. Circumferential stretching of saphenous vein smooth muscle enhances vasoconstrictor responses by Rho kinase-dependent pathways. Cardiovasc Res. 2002;53: 219-26.

29. Stooker W, Gok M, Sipkema P, Niessen HW, Baidoshvili A, Westerhof N, et al. Pressure-diameter relationship in the human greater saphenous vein. Ann Thorac Surg. 2003;76:1533-8.

30. Papadopoulos NJ, Sherif MF, Albert EN. A fascial canal for the great saphenous vein: gross and microanatomical observations. J Anat. 1981;132(Pt 3):321-9.

31. Bosher LP, Deck JD, Thubrikar M, Nolan SP. Role of the venous valve in late segmental occlusion of vein grafts. J Surg Res. 1979;26:437-46.

32. Rusch N, Wooldridge T, Kulig C, Almassi G, Nicolosi A, Olinger G, et al. Reactivity of human saphenous veins at arterial perfusion pressures. J Thorac Cardiovasc Surg. 1995;110(4 Pt 1):1005-12.

33. Edwards WS, Holdefer WF, Mohtashemi M. The importance of proper caliber of lumen in femoral-popliteal artery reconstruction. Surg Gynecol Obstet. 1966;122: 37-40.

34. Barker WF, Crawford ES, Mannick JA, Wylie EJ. The current status of femoropopliteal bypass for arteriosclerotic occlusive disease: a panel discussion. Surgery. 1976;79:30-6.

35. Sonnenfeld T, Cronestrand R. The advantages of the great saphenous vein as a femoropopliteal graft. A report on its clinical use. Scand J Thorac Cardiovasc Surg. 1980;14:285-90.

36. Koontz TJ. Stansel HC Jr. Factors influencing patency of the autogenous vein femoropopliteal bypass graft: an analysis of 74 cases. Surgery. 1972;71:753-9.

37. LoGerfo F, Haudenschild C, Quist W. A clinical technique for prevention of spasm and preservation of endothelium in saphenous vein grafts. Arch Surg. 1984;119:1212-4. 
38. Dodge JT Jr, Brown BG, Bolson EL, Dodge HT. Lumen diameter of normal human coronary arteries. Influence of age, sex, anatomic variation, and left ventricular hypertrophy or dilation. Circulation. 1992;86:232-46.

39. Kohler T, Kirkman T, Kraiss L, Zierler B, Clowes A. Increased blood flow inhibits neointimal hyperplasia in endothelialized vascular grafts. Circ Res. 1991;69: 1557-65.

40. Levesque M, Liepsch D, Moravec S, Nerem R. Correlation of endothelial cell shape and wall shear stress in a stenosed dog aorta. Arteriosclerosis. 1986;6: 220-9.

41. Bach RG, Kern MJ, Donohue TJ, Aguirre FV, Caracciolo EA. Comparison of phasic blood flow velocity characteristics of arterial and venous coronary artery bypass conduits. Circulation. 1993;88(5 Pt 2):II133-40.

42. Brody WR, Angeli WW, Kosek JC. Histologic fate of the venous coronary artery bypass in dogs. Am J Pathol. 1972;66:111-30.
43. Davies A, Magee T, Baird R, Sheffield E, Horrocks M. Pre-bypass morphological changes in vein grafts. Eur J Vasc Surg. 1993;7:642-7.

44. Kouzi-Koliakos K, Kanellaki-Kyparissi M, Marinov G, Knyazhev V, Tsalie E, Batzios C, et al. Prebypass histological and ultrastructural evaluation of the long saphenous vein as a predictor of early graft failure. Cardiovasc Pathol. 2006; 15:336-46.

45. Cheanvechai C, Effler DB, Hooper JR, Eschenbruch EM, Sheldon WC, Sones FM Jr, et al. The structural study of the saphenous vein. Ann Thorac Surg. 1975;20:636-45.

46. Spray TL, Roberts WC. Changes in saphenous veins used as aortocoronary bypass grafts. Am Heart J. 1977;94:500-16.

47. Buxton B, Lambert RP, Pitt TT. The significance of vein wall thickness and diameter in relation to the patency of femoropopliteal saphenous vein bypass grafts. Surgery. 1980;87:425-31. 